\title{
MAPEAMENTO DAS MANIFESTAÇÕES PATOLÓGICAS NAS FACHADAS DO SEMINÁRIO E IGREJA DE NOSSA SENHORA DA GRAÇA
}

\author{
BENTO, ADEGILSON \\ Engenheiro Civil \\ Universidade de Pernambuco \\ Pernambuco; Brasil \\ ajb_pec@poli.br
}

\author{
GUSMÃO, ALEXANDRE \\ Professor \\ Universidade de Pernambuco \\ Pernambuco; Brasil \\ alexandreduartegusmao@gmail.com
}

\author{
NEVES, DANIELY \\ Engenheira Civil \\ Universidade de Pernambuco \\ Pernambuco; Brasil \\ dcmn_pec@poli.br
}

\author{
LORDSLEEM JÚNIOR, ALBERTO \\ Professor \\ Universidade de Pernambuco \\ Pernambuco; Brasil \\ acasado@poli.br
}

\section{RESUMO}

Construido na metade do século 16, o conjunto arquitetônico formado pela Igreja de Nossa Senhora da Graça e pelo antigo Seminário, representa um marco da arquitetura jesuíta no Brasil e compõe o Sítio Histórico de Olinda. Como todo monumento histórico as fachadas da Igreja de Nossa da Graça e o antigo seminário sofrem com a deteriorioração ao longo do tempo. Diante do exposto, o presente trabalho tem como objetivo avaliar o estado de conservação das fachadas externas do conjunto, investigando as causas das manifestações patológicas encontradas no elemento, propondo intervenções para a melhoria da estrutura e prolongamento da vida útil da edificação religiosa. A metodologia adota seguiu as seguintes etapas: levantamento histórico da estrutura, elaboração dos projetos de fachada, Inspeção visual do Seminário e Igreja de Nossa Senhora da Graça adotando a Norma de Inspeção Predial Nacional do Instituto Brasileiro de Avaliações e Perícias de Engenharia - IBAPE, para realizar uma avaliação sistêmica da edificação, elaboração dos mapas de danos, proposta de intervenção em cada manifestação patológica e elaboração de um plano de manutenção preventiva. Os resultados demonstraram que as fachadas apresentam incidência de alguma manifestação patológica, sendo a crosta negra a mais comum entre elas. Adotar um plano de manutenção preventiva é essencial para recuperação das fachadas, devolvendo assim estética e segurança para esse ícone da história pernambucana.

Palavras-chave: inspeção, fachadas, igrejas históricas.

\section{ABSTRACT}

Built in the middle of the 16th century, the architectural complex formed by the Our Lady of Grace Church and the old Seminary, represents a landmark of Jesuit architecture in Brazil and it is part of the Olinda Historical Site. As every historical monument, the facades of the Our Lady of Grace Church and the Seminary suffer with deterioration over time. Thus, this work aims to evaluate the conservation status of the exterior facades of the complex, investigating the causes of the pathological manifestations found in the element, proposing interventions to improve the structure and prolong the life cycle of the religious building. The methodology followed adopts the following steps: historical survey of the structure, elaboration of projects of facade, visual inspection of the Seminary and Church of Our Lady of Grace by adopting the national standard Building Inspection of the Instituto Brasileiro de Avaliações e Perícias de Engenharia IBAPE, to perform a systemic evaluation of building, preparation of damage maps, proposal of intervention for each the pathological manifestations found and elaboration of a preventive maintenance plan. The results showed that the facades have an incidence of some pathological manifestation, being the most common on the black crust. Adopting a preventive maintenance plan is essential for recovery of the facades, thus restoring aesthetics and security for this icon in the history of Pernambuco.

Keywords: inspection, facade, historical churches. 


\section{INTRODUÇÃO}

A conservação é importantíssima no que diz respeito a monumentos históricos, como é o caso Igreja de Nossa Senhora da Graça e do antigo Seminário de Olinda - PE, cidade patrimônio histórico da humanidade, uma vez que tais edificações têm um valor cultural inigualável para a população local, que é levado através das gerações, além de toda a simbologia que representa. Levando esse panorama em consideração, chega-se ao momento de realizar a investigação e percebe-se que tal estudo não faz parte apenas da construção civil. Deve ser feito, na realidade, um estudo multidisciplinar e interligado, juntando-se princípios de: Arquitetura, uma vez que é a responsável pelo desenho das edificações; história, que traz aspectos ao longo dos séculos que explicam as características da construção; um ponto que procura apresentar a ligação da estrutura com as pessoas que a circundam, a sociologia; entre outras, para assim explicar a origem das manifestações patológicas.

Para, Vieira (2016, p. 05) as "manifestações patológicas aos quais as edificações estão expostas podem ocorrer em qualquer fase, considerando que cada fase haverá um responsável”. Para Ferreira e Lobão (2018) é possível dividir a origem dos problemas patológicos da seguinte forma:

- Congênitas: Estão ligadas a fase de projeto, é possível dizer que nascem com a estrutura, se dão pelo esquecimento de itens fundamentais de durabilidade, durante a concepção da mesma como, por exemplo, o descuido com as especificações de durabilidade de elementos arquitetônicos, que embora em alguns casos possam não ter responsabilidade estrutural, favorecem a aparecimento e desenvolvimento de manifestações patológicas, especialmente em ambientes agressivos.

- Construtivas: Se dão na fase de execução, assim como as congênitas, essa causa acontece com o surgimento da estrutura, principalmente pela falta de cuidado durante a realização de algum elemento ou até mesmo, erros na execução de determinada etapa construtiva.

- Adquiridas: Acontecem durante o uso e manutenção da edificação, visto que a vida útil da edificação está atrelada a uma rotina adequada de manutenção, sendo esta uma etapa determinante na prevenção da deterioração é do desenvolvimento de algumas manifestações patológicas, visto que, nem todas as partes de uma obra, terá o mesmo tempo de uso.

- Acidentais: Esta causa está relacionada aos fenômenos atípicos que podem acometer a estruturas, como choques e incêndios, que acabam por fragilizá-la e propiciar a instalação de diversos problemas na estrutura.

Investigar as manidestações patológicas e suas origens é fundamental para elaboração de um plano de manutenção que resulte em uma recuperação correta, sendo a inspeção visual a técnica mais utilizada nesse tipo de avaliação, uma vez que possui uma metodologia simples que não inclui apenas o levantamento dos defeitos patológicos, mas também de suas características construtivas e detalhes como condições ambientais em que está inserida. Consiste muitas vezes de levantamentos feitos a olho nu ou até mesmo com auxílio de máquinas de filmar, ou fotográficas, que são equipamentos do mesmo modo simples, favorecendo sua ampla adoção. Existem indicações de orgãos como IPHAN (Instituto do Patrimônio Histórico e Artístico Nacional) de metodologias para regulamentação dos mecanismos de inpeção, no entato ainda não há uma normatizações que indiquem ou determinem qual o melhor procedimento para a ser seguido ( ROCHA, 2018; SALES et al., 2018).

O presente trabalho tem como objetivo principal a investigação de manifestações patológicas das fachadas principais do monumento histórico da cidade de Olinda - PE, a Igreja de Nossa Senhora da Graça e o Seminário de Olinda, para realização de um diagnóstico a partir dos dados coletados, em forma de um documento gráfico-fotográfico conhecido como Mapa de Danos, que poderá eventualmente servir como registro importante para elaboração de um plano de manutenção por parte dos órgãos públicos de revitalização, responsáveis por esse tipo de edificação, como o IPHAN e a própria Prefeitura da Cidade de Olinda.

\section{CARACTERIZAÇÃO DA EDIFICAÇÃO}

A edificação está localizada na Rua Bispo Coutinho, S/N - Carmo, Olinda - PE (Figura 1). Construído na metade do século 16, mais precisamente no ano de 1550, pelo então capitão donatário de Pernambuco, Duarte Coelho, sendo na 
época uma ermida ${ }^{1}$ em taipa, localizada na colina mais alta de Olinda, o conjunto arquitetônico formado pela Igreja de Nossa Senhora da Graça e pelo antigo Seminário, representa um marco da arquitetura jesuíta no Brasil compondo assim o Sítio Histórico de Olinda (Instituto do Patrimônio Histórico e Artístico Nacional - IPHAN, 2010).

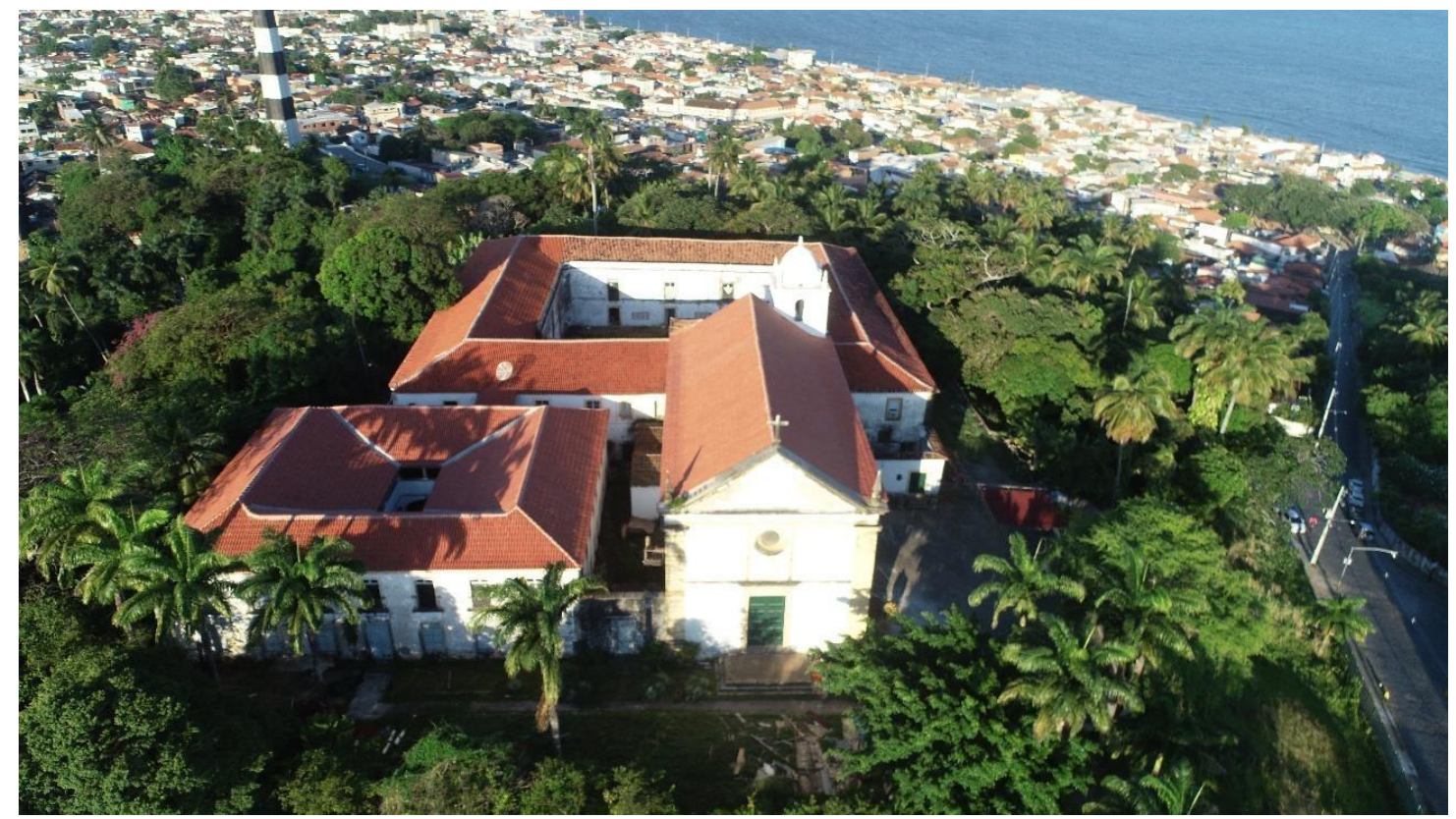

Figura 1 - Seminário de Olinda e Igreja de Nossa Senhora da Graça. Fonte: Autores.

Segundo o IPHAN (2010), em 1563 aconteceu a primeira reforma na igreja, com duração de quatro anos, não sendo a única reforma pela qual a edificação passou, sua estrutura foi modificada também entres os anos de 1584 e 1592 , mais tarde, com os incêndios causados na cidade de Olinda durante a invasão holandesa, teve sua estrutura gravemente afetada, assim preciosu ser reconstruída, o que ocorreu apenas em 1661. Com a expulsão da Companhia de Jesus em 1759 por ordem do Marques de Pombal a estrutura ficou abandonada até 1796 quando foi doada para nele funcionar o Seminário Episcopal de Nossa Senhora da Graça ou Seminário de Olinda, sendo reaberto em 1800 (IPHAN, 2010).

Em 1975, o conjunto foi restaurado sob supervisão do Serviço do Patrimônio Histórico e Artístico Nacional (SPHAN), orgão responsável pelo patrimonio histórino nacional da época, contudo encontra-se interditado desde em 2015 pela Defesa Civil, que na ocasião informou que as instalações estariam comprometidas e representariam alto risco para a estrutura e para as pessoas que visitam e residiam no local (JC ONLINE, 2015).

O seminário é composto por dois pavimentos, com ambientes como dormitórios, biblioteca, refeitório e sala de convivência e possui ainda um jardim interno e uma edificação anexa, onde funcionou a primeira Faculdade de Arquitetura e a primeira Escola de Agronomia, também com dois pavimentos, 4 salas amplas, totalizando uma área construída de aproximadamente 2.700,00 $\mathrm{m}^{2}$ (dois mil e setecentos metros quadrados). Por fim, a Igreja de Nossa Senhora da Graça, composta por uma nave única com aproximadamente 14 metros de largura, 32 metros de comprimento e 7 metros de pé direito, totaliza uma área de aproximadamente $440,00 \mathrm{~m}^{2}$ (quatrocentos e quarenta metros quadrados).

Preservaram-se ao longo do tempo algumas características da edificação original, como as alvenarias em tijolo maciço, com ornamentações em pedra, janelas e portas de madeira, coberta em estrutura de madeira e telha francesa, porém algumas intervenções foram realizadas nas fachadas onde é possível perceber reparos em argamassa de Cimento Portland, descaracterizando parte da construção.

Como histórico de intervenções tem-se que em 2019 foi contratada uma empresa para realizar apenas o conserto da coberta da nave da igreja, assoalho da área de bedelagem e as rachaduras da fachada, posteriormente se adicionando a esse contrato a troca do telhado de parte do seminário.

\footnotetext{
${ }^{1}$ Ermida: capela ou igreja situada em local afastado.
} 


\section{METODOLOGIA}

As vistorias foram realizadas na edificação que abriga o Seminário de Olinda e Igreja de Nossa Senhora da Graça nos dias 27.08.2019, no período da tarde, 12.09.2019 no período da manhã e no dia 25.09.2019 no período da tarde. A metodologia está dividida nas 4 etapas indicadas na Figura 2.

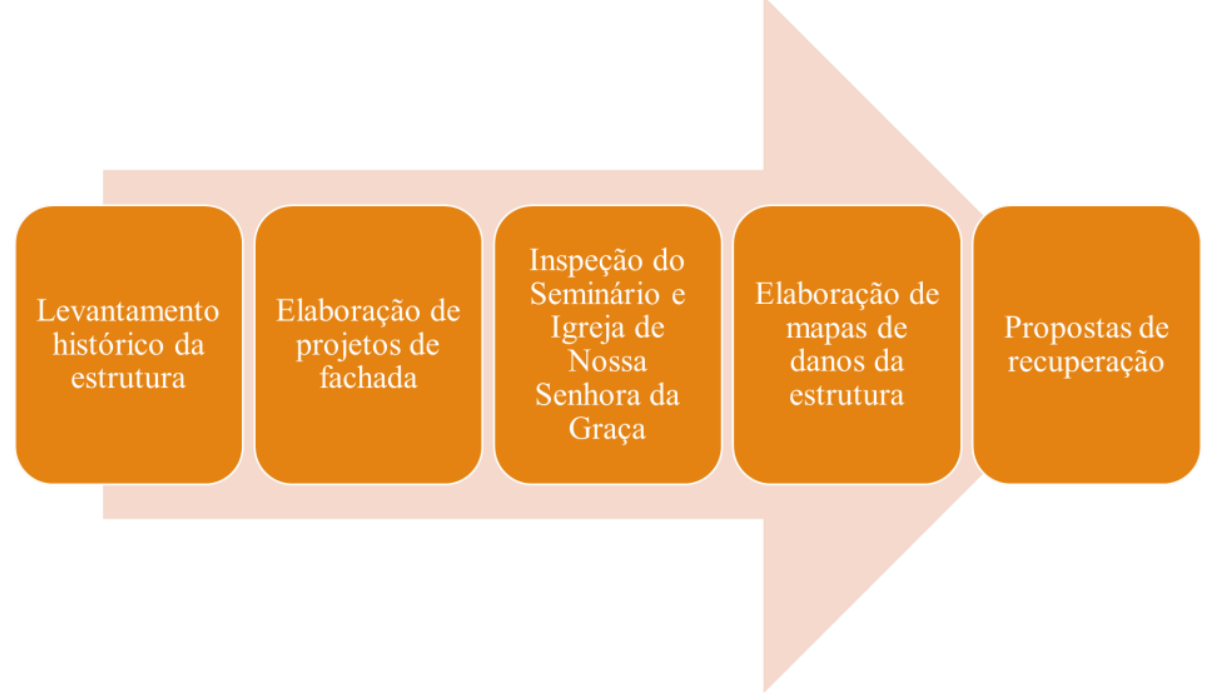

Figura 2 - Etapas da metodologia

Inicialmente, realizou-se o levantamento histórico da estrutura, registrando o contexto geral em que a obra está inserida através de coleta de dados e catalogando todo o material já existente sobre a estrutura. Em seguida, foram elaborados os projetos arquitetônicos das fachadas com o auxílio do software AutoCAD, para facilitar identificação das estruturas e as características funcionais, além de indicar, classificar e quantificar a gravidade de todos os sintomas visuais encontrados através de registros fotográficos com o intuito de produzir os mapas de danos das fachadas.

Por fim, foram estabelecidas propostas de recuperação das manifestações patológicas através do diagnóstico, etapa de análise dos resultados obtidos no estudo das manifestações patológicas e compreensão dos sintomas, causas e origens, bem como os prognósticos, definindo a conduta a ser adotada para garantir a integridade da estrutura e/ou aumentar, quando possível, sua vida útil.

A inspeção, em acordo com o que estabelece o Instituto Brasileiro de Avaliações e Perícias de Engenharia - IBAPE na Norma de Inspeção Predial Nacional (2012), busca definir a gravidade, risco e urgência da intervenção.

\section{RESULTADOS}

\subsection{Manifestações patológicas encontradas.}

Por se tratar de uma edificação antiga que vem passando por reparos e não se encontra habitada, algumas das manifestações patológicas encontram-se em estágio avançado. A seguir listam-se as principais manifestações patológicas encontradas, sua gravidade, risco e urgência.

\subsubsection{Ataques Biológicos ou Biodeterioração}

Bolor, mofo ou limo decorrentes da colonização por diversas populações de bactérias, fungos filamentosos e micro vegetais que se alimentam de materiais orgânicos formando manchas sobre a superfície atacada. 

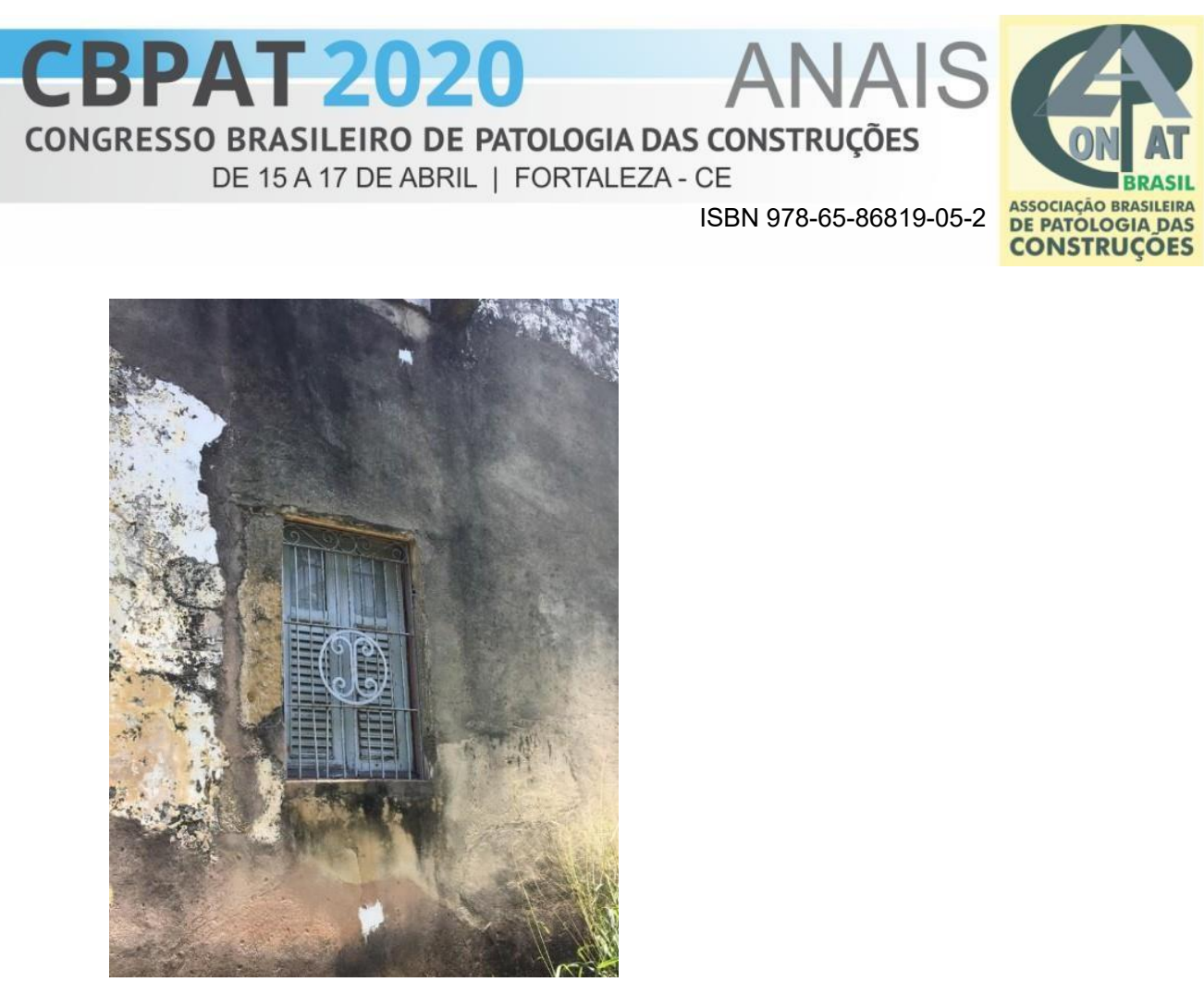

Figura 3 - Exemplo de bolor

Classificado quanto ao grau de risco como CRÍTICO, considerando o alto risco oferecido à saúde dos usuários, uma vez esses microorganismos são responsáveis por diversas doenças respiratórias.

\subsubsection{Cupins}

$\mathrm{O}$ ataque de insetos às estruturas de madeiras. Os cupins ou térmitas são tipos de xilófagos que se alimentam da celulose da madeira quando estado adulto.

Quanto ao grau de risco, pode ser classificado como MÉDIO, uma vez que pode causar perda parcial de desempenho caso entre em contato com esquadrias de madeira ou a estrutura do telhado, afetando a funcionalidade do elemento, além de causar prejuízo à estética.

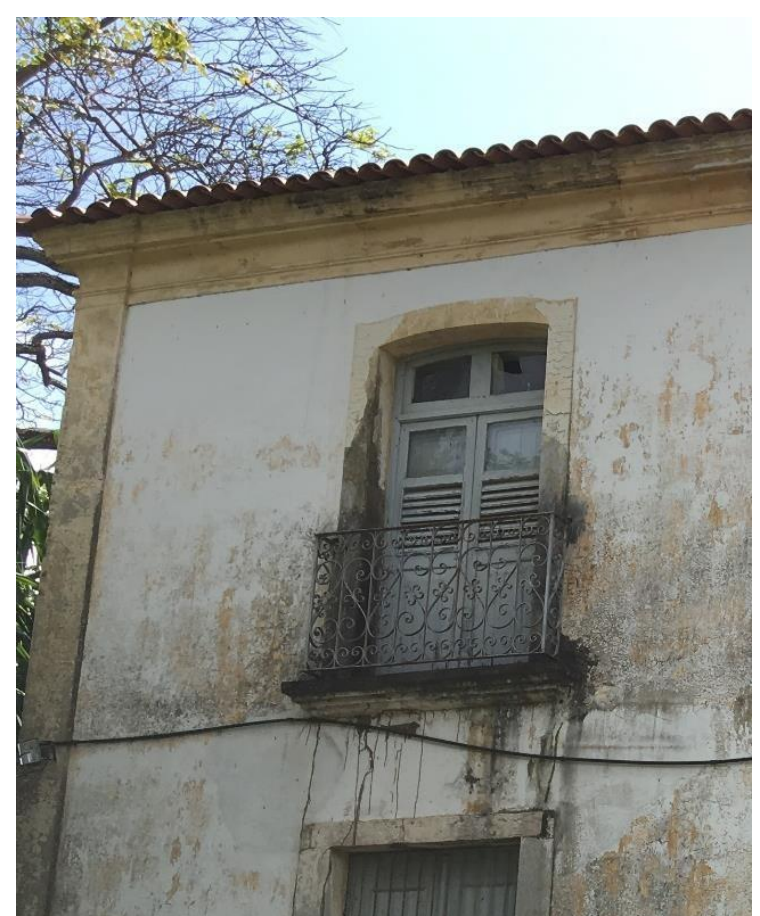

Figura 4 - Manifestação de cupim acima de esquadria 


\subsubsection{Descascamento de Pintura}

Caracteriza-se pelo descolamento dos revestimentos em pintura.

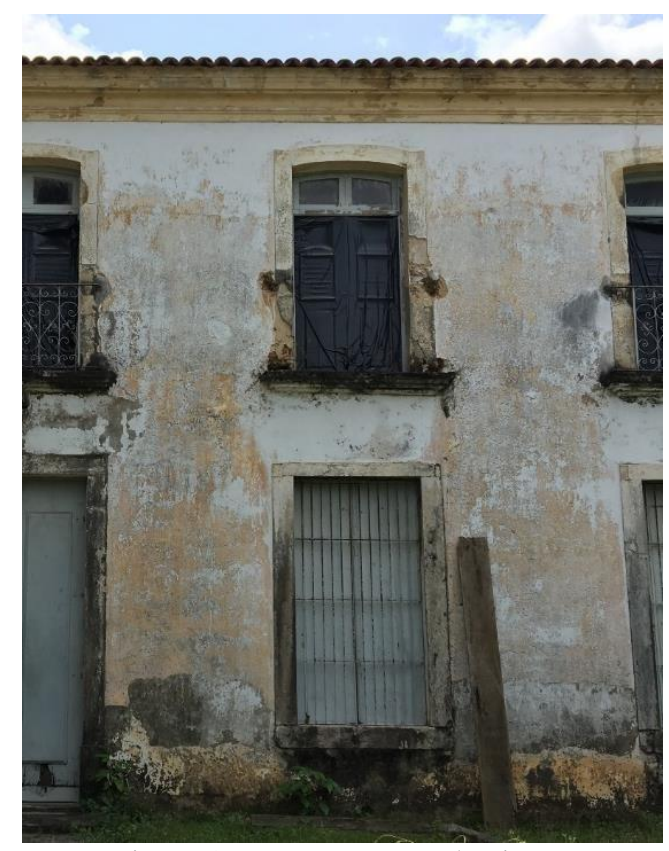

Figura 5 - Descascamento de Pintura

Classificado quanto ao grau de risco como CRÍTICO, considerando que afeta significativamente o desempenho e funcionalidade do sistema ao facilitar a absorção de água na alvenaria, podendo ocasionar novas manifestações patológicas.

\subsubsection{Desagregação granular}

A desagregação granular é provocada pelo intemperismo natural das rochas areníticas que compõem a edificação.

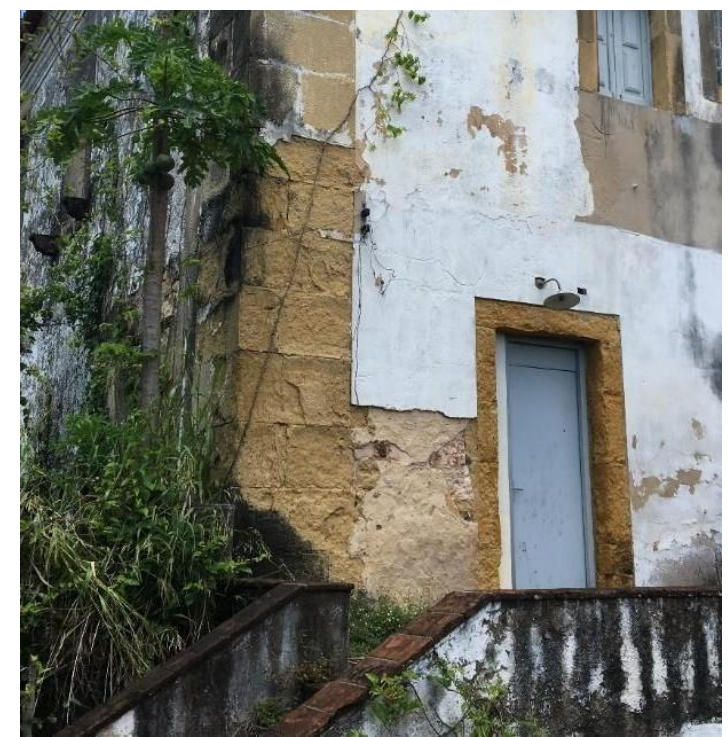

Figura 6 - Desagregação granular 
Classificado quanto ao grau de risco como CRÍTICO, considerando o alto risco oferecido aos usuários, com perda excessiva de desempenho e funcionalidade do sistema e comprometimento da vida útil, uma vez que é a estrutura propriamente dita da edificação.

\subsubsection{Desplacamento do revestimento}

Desplacamento do reboco e a presença de umidade, seja esta por meio de infiltrações generalizadas ou por capilaridade (umidade ascensional). Percebe-se que em muitos pontos do reboco encontra-se esfarelado e se desprendendo com facilidade da superfície.

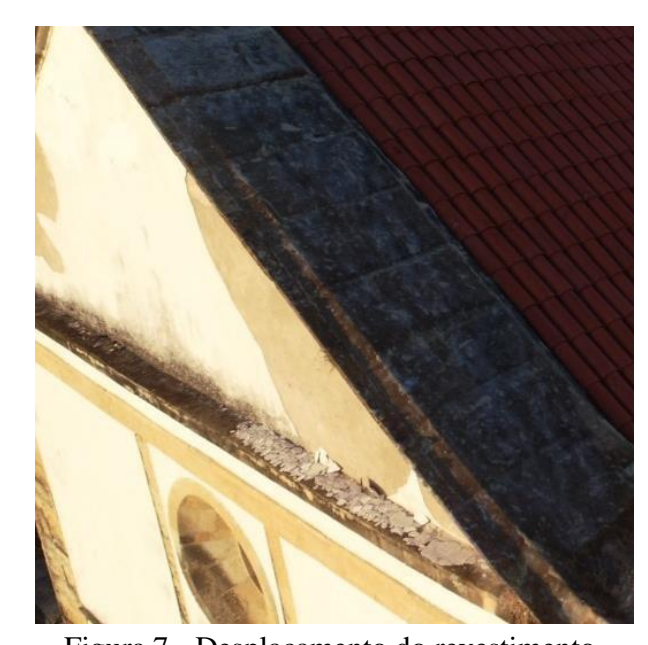

Figura 7 - Desplacamento do revestimento

Classificado quanto ao grau de risco como CRÍTICO, considerando que afeta significativamente o desempenho e funcionalidade do sistema, pois pode ocasionar novas manifestações patológicas ao facilitar a passagem de umidade do lado externo para a área interna.

\subsubsection{Deterioração das esquadrias}

A exposição dos elementos de madeira aos agentes atmosféricos promove a deterioração dos mesmos. Ao mesmo tempo o apodrecimento da madeira também pode ser provocado por bactérias e algas.

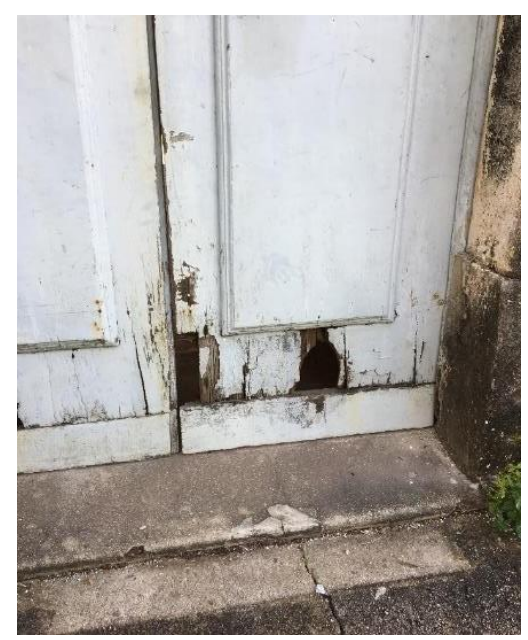

Figura 8 - Deterioração das esquadrias

O grau de risco é classificado como MÉDIO, pois além de afetar a estética, a depender do nível de deterioração, pode permitir a entrada de animais na edificação, tendo o seu desempenho de vedação prejudicado. 


\subsubsection{Fissuração}

Quadros fissuratórios de outros materiais construtivos, também podem contribuir para o desenvolvimento de outros problemas patológicos e consequente deterioração do material.

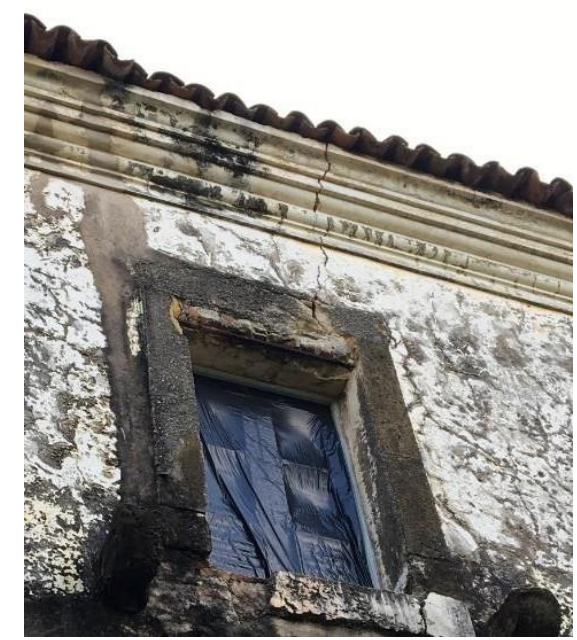

Figura 9 - Fissuração

Classificado quanto ao grau de risco como CRÍTICO, considerando o alto risco, caso sejam profundas, de ocasionar o destacamento do material e atingir os usuários.

\subsubsection{Vegetação}

Ação da biodeterioração na fachada, com o desenvolvimento de vegetação.

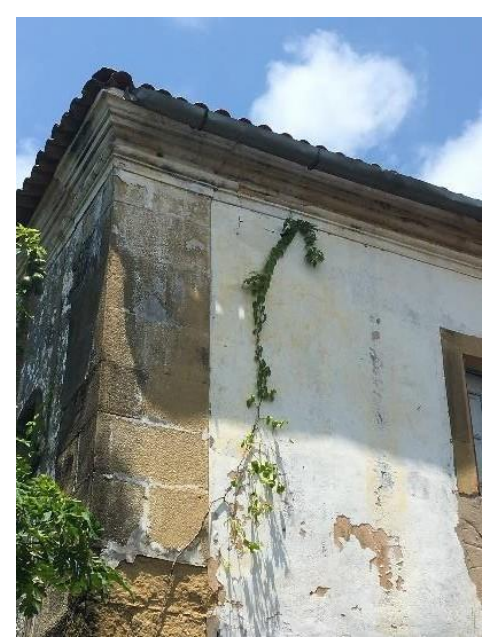

Figura 10 - Presença de vegetação

Classificado quanto ao grau de risco como MÍNIMO, conferindo à edificação apenas um dano estético.

Neste aspecto, é importante ressaltar a ação degradante dos dejetos de aves que se depositam nas partes superiores da edificação contribuindo para a proliferação de doenças e para a degradação dos materiais construtivos. 


\subsection{Mapa de danos das fachadas}

O mapa de danos é uma representação gráfico-fotográfica na qual são ilustradas e locadas todas as manifestações patológicas observadas e analisadas na estrutura das edificações em determinada data ou período de tempo (TINOCO, 2009). Com base em projetos fornecidos pela Arquidiocese, foram produzidos os mapas abaixo:

\subsubsection{Fachada frontal}

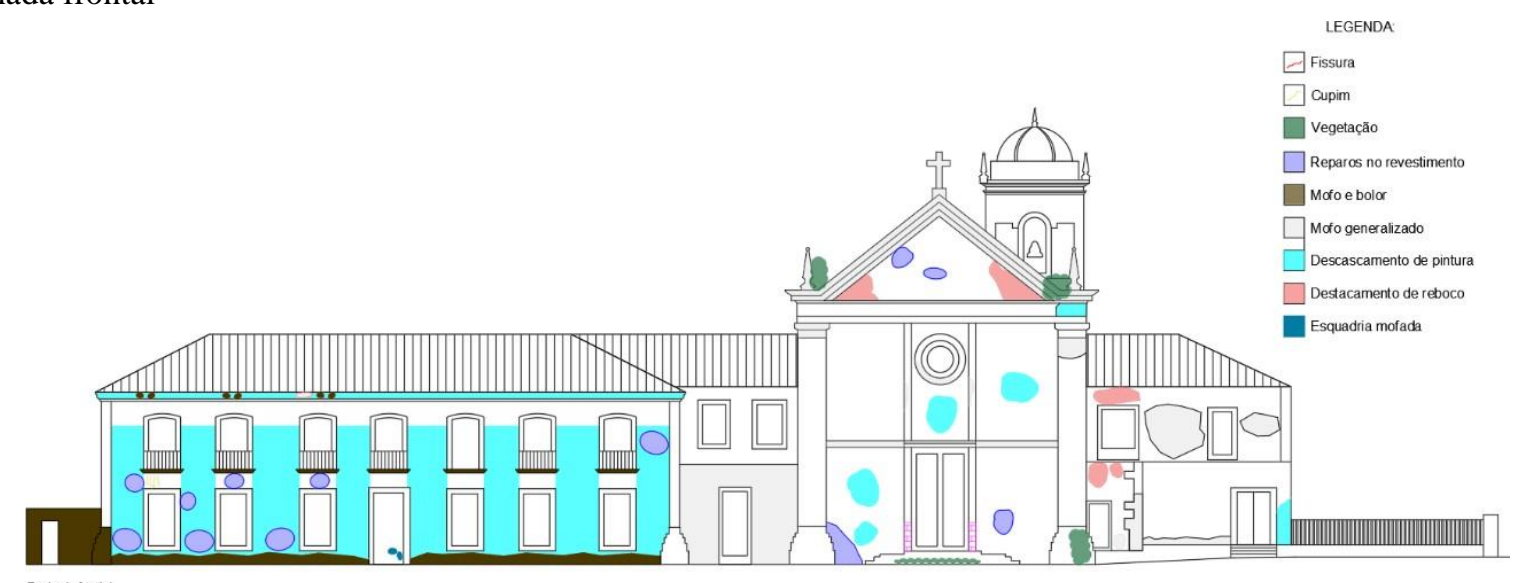

Fachada trontal
Esc: Sem escaia

Figura 11 - Representação das manifestações patológicas na fachada frontal.

4.2.2 Fachada lateral direita

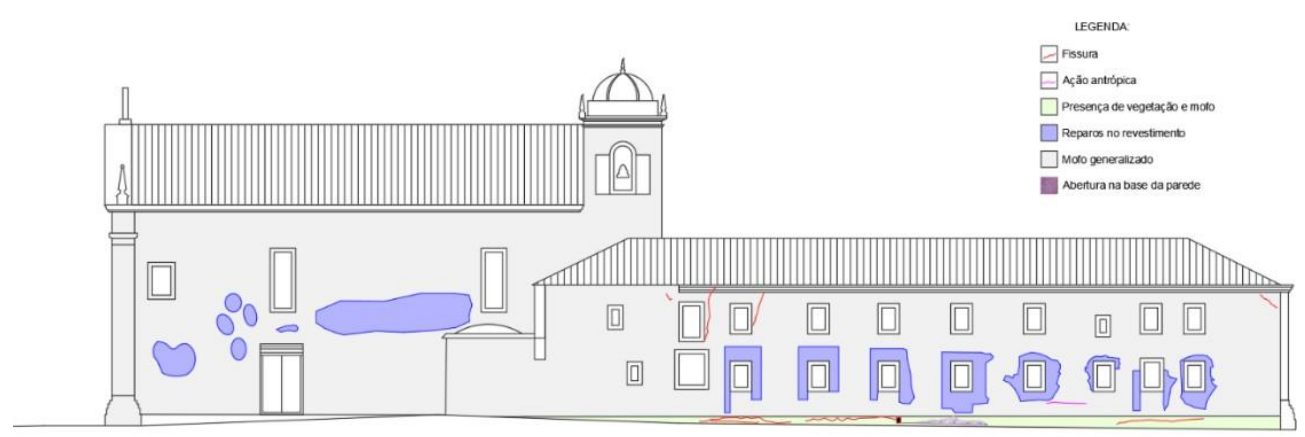

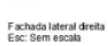

Figura 12 - Representação das manifestações patológicas na fachada frontal.

4.2.3 Fachada lateral esquerda

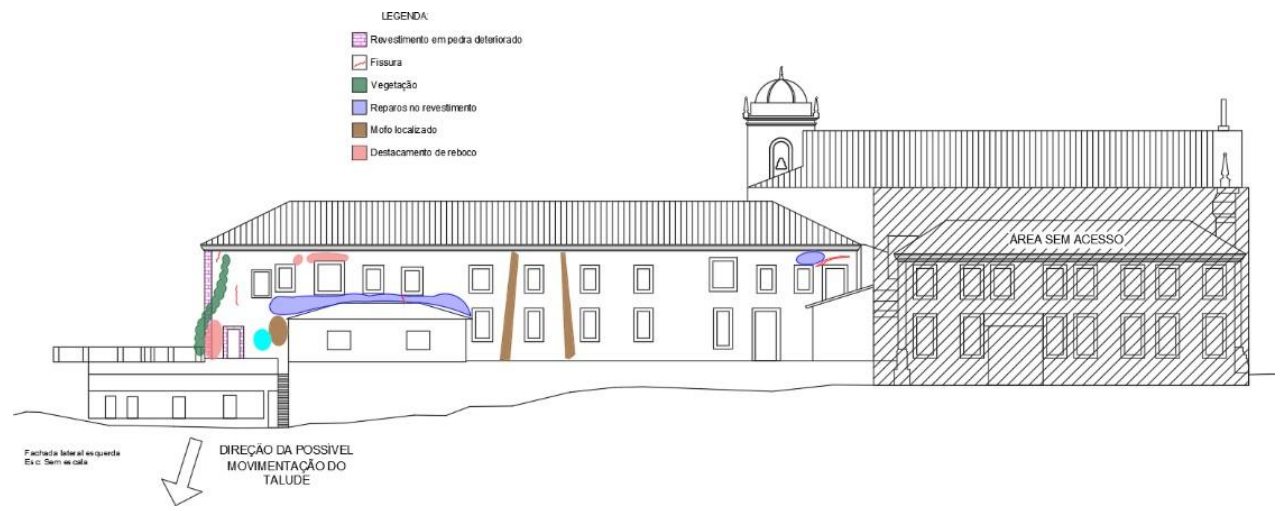

Figura 13 - Representação das manifestações patológicas na fachada frontal. 
4.2.4 Fachada posterior

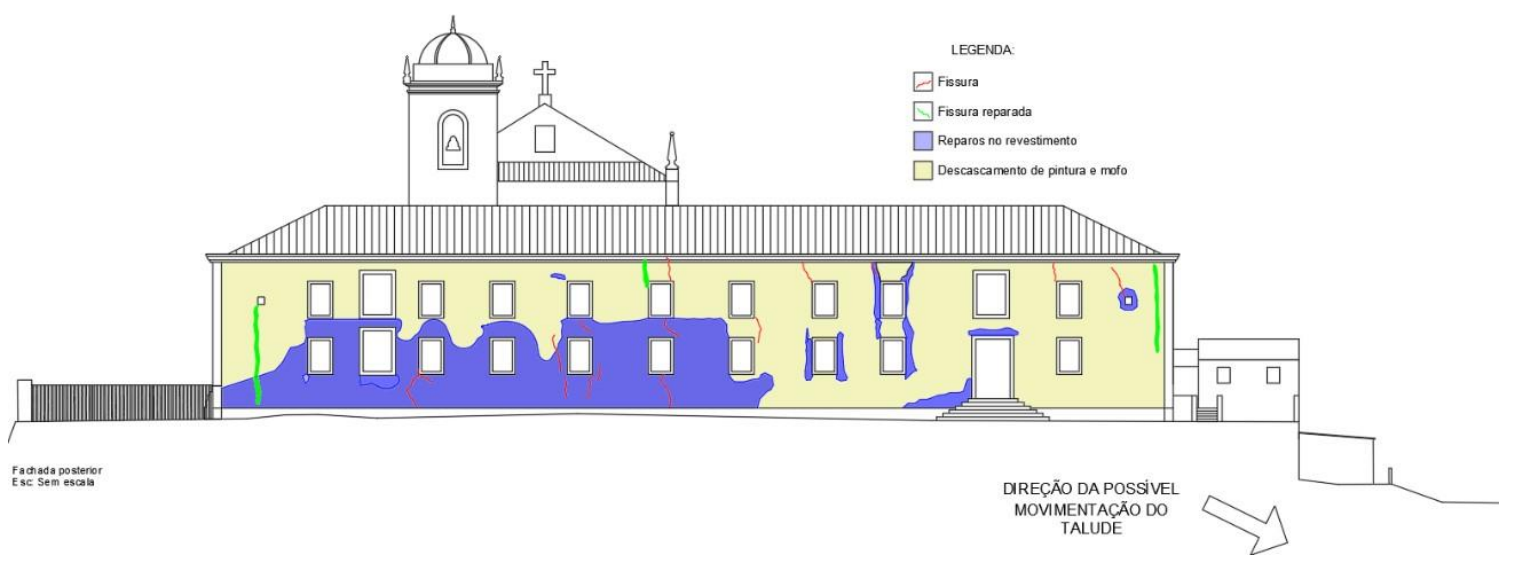

Figura 14 - Representação das manifestações patológicas na fachada frontal.

\subsection{Propostas de recuperação}

De acordo com a manifestação patológica encontrada e o nível de degradação em que o elemento se encontra, é necessário realizar intervenções para recuperá-lo por completo e restituir a sua função original. Algumas medidas comuns de recuperação estão dispostas na Tabela 1.

Tabela 1 - Propostas de recuperação

\begin{tabular}{|c|c|}
\hline MANIFESTAÇÃO PATOLÓGICA & RECUPERAÇÃO \\
\hline Ataques Biológicos ou Biodeterioração & $\begin{array}{l}\text { Para solucionar estes problemas será preciso descascar todo } \\
\text { o revestimento degradado, refazê-lo com aplicação prévia de } \\
\text { produtos impermeabilizantes misturados à massa e pintura } \\
\text { acrílica para cada área em questão. }\end{array}$ \\
\hline Cupins/ Deterioração das esquadrias & $\begin{array}{l}\text { Controle de cupins, atraves da aplicação de inseticidas } \\
\text { solventes aplicados nas areas atingidas; Substituição de } \\
\text { algumas partes da coberta e esquadrias. }\end{array}$ \\
\hline $\begin{array}{c}\text { Descascamento de Pintura e } \\
\text { Desplacamento do revestimento }\end{array}$ & $\begin{array}{l}\text { Restauração total do revestimento da alvenaria, com a } \\
\text { retirada do revestimento anterior para nova aplicação de } \\
\text { chapisco, emboço e reboco em toda a região (REITEC, } \\
\text { 2017, apud NÓBREGA et al, 2017) }\end{array}$ \\
\hline Desagregação granular & $\begin{array}{l}\text { Limpeza da pedra, limpeza e preenchimento das juntas, } \\
\text { eliminação da colonização biológica, consolidação das áreas } \\
\text { mais intensamente afetadas por desagregação granular, } \\
\text { hidrofugação das superfícies tratadas (CARDOSO, 2008) }\end{array}$ \\
\hline Fissuração & $\begin{array}{l}\text { Colocação de vergas e contravergas de concreto armado; } \\
\text { Aplicação de produtos flexíveis, como selantes elásticos. } \\
\text { Reforço estrutural para prevenir a expansao das aberturas, } \\
\text { atraves de pilares e vigas de amarração sobre as paredes. }\end{array}$ \\
\hline Vegetação & $\begin{array}{l}\text { Remover e utilizar produtos químicos para evitar o } \\
\text { reaparecimento da manifestação. }\end{array}$ \\
\hline
\end{tabular}

Fonte: Adaptado de Nóbrega et al. (2017)

\subsection{Programa de manutenção preventiva}

Para Gomide, Neto e Pujadas (2006), o plano de manutenção orienta as atividades de manutenção e as rotinas de operação, consoante uma estratégia, através de um conjunto de informações e procedimentos (diretrizes), consoante uma estratégia. Esse plano visa atingir um objetivo baseados em etapas pré-estabelecidas. Pode definir as seguintes definições para um plano de manutenção: 
- Detalhamento de rotinas.

- Detalhamento de procedimentos.

- Periodicidade.

- Parâmetros de fabricante quanto ao uso e inspeção rotineira de componentes.

- Dados sobre eventuais falhas decorrentes de uso, operação ou deficiência nos

- procedimentos listados.

- Observações quanto a procedimentos de urgência.

- Periodicidade para o feedback e nível de suficiência das informações que serão

- coletadas e registradas.

- Registro e histórico de atividades de manutenção.

- Dados de referência quanto ao custo médio de cada atividade do plano.

- Outros, dependendo da estratégia de Manutenção implantada.

Observados os aspectos conceituais de estratégia e plano de manutenção, as atividades inerentes podem ser classificadas em: preditiva, consiste em intervir na iminência de uma falha, detectada através do monitoramento; preventiva, quando se tratar de ajustes, conservação e eliminação de defeitos, visando evitar falhas; corretiva; trata-se dos reparos, planejados ou não para correção de falhas e detectiva, tem como objetivo levantar as causas do problema e falhas para sua análise e auxiliando no plano de manutenção.

Para as fachadas da edificação estudada é possível propor as seguintes atividades para caracterizar um plano de manutenção, com base na NBR 5674 (ABNT, 2012). A tabela 2 apresenta uma proposta de plano de manutenção para fachadas.

Tabela 2 - Proposta de plano de manutenção

\begin{tabular}{|c|c|c|c|}
\hline Periodicidade & $\begin{array}{c}\text { Elemento / } \\
\text { Componente }\end{array}$ & Atividade & Responsável \\
\hline \multirow{3}{*}{ A cada ano } & \multirow{2}{*}{ Fachada } & $\begin{array}{l}\text { Verificar a calafetação e fixação de rufos, para-raios, antenas, } \\
\text { esquadrias, elementos decorativos etc. }\end{array}$ & $\begin{array}{l}\text { Empresa capacitada } \\
\text { Empresa especializada }\end{array}$ \\
\hline & & $\begin{array}{l}\text { Verificar sua integridade e reconstituir, paredes, soleiras, } \\
\text { grelhas de ventilação e outros elementos arquitetônicos. }\end{array}$ & $\begin{array}{l}\text { Empresa capacitada } \\
\text { Empresa especializada }\end{array}$ \\
\hline & $\begin{array}{l}\text { Paredes externas / } \\
\text { fachadas e muros }\end{array}$ & Verificar integridade e reconstituir, onde necessário & $\begin{array}{l}\text { Equipe de manutenção local } \\
\text { / Empresa especializada }\end{array}$ \\
\hline \multirow{3}{*}{$\begin{array}{l}\text { A cada três } \\
\text { anos }\end{array}$} & \multirow{3}{*}{ Fachada } & Efetuar lavagem. & \multirow[b]{2}{*}{$\begin{array}{l}\text { Equipe de manutenção local } \\
\text { / Empresa capacitada / } \\
\text { Empresa especializada }\end{array}$} \\
\hline & & $\begin{array}{l}\text { Verificar os elementos, por exemplo:, campanários, cachorros, } \\
\text { e demais molduras presentes na fachada e se necessário, } \\
\text { solicitar inspeção especializada. }\end{array}$ & \\
\hline & & $\begin{array}{l}\text { As áreas externas devem ter sua pintura revisada e, se } \\
\text { necessário, repintada, evitando assim o envelhecimento, a } \\
\text { perda de brilho, o descascamento e que eventuais fissuras } \\
\text { possam causar infiltrações. }\end{array}$ & $\begin{array}{l}\text { Equipe de manutenção local } \\
\text { / Empresa capacitada }\end{array}$ \\
\hline
\end{tabular}

\section{CONSIDERAÇÕES FINAIS}

Estruturalmente não foi detectado nenhum risco durante a inspeção visual da área externa. Foi verificado, através de selos de gesso, que as fissuras da fachada estão trabalhando, o que comprova que existe uma movimentação, apesar de não comprometer a estabilidade da obra. A possível causa da movimentação é infiltração de água pelo terreno que afeta a crista viva do talude. A área do alojamento possui seteiras que permitem a visualização de uma possível fundação de pedra, o que influenciaria positivamente na estabilização do terreno. Na lateral direita verificou-se afundamento de aproximadamente $10 \mathrm{~cm}$ relativo ao movimento da encosta.

Sugere-se à Arquidiocese que sejam instalados pinos e sensores para a medição de recalque e movimentação do terreno, para que sejam planejadas as manutenções adequadas. Indica-se o processo de conservação do seminário para possibilitar a desinterdição, pois quando mais tempo inabitado, maior a velocidade de degradação. 


\section{REFERÊNCIAS}

ASSOCIAÇÃO BRASILEIRA DE NORMAS TÉCNICAS - ABNT. NBR 5674: Manutenção de edificações Requisitos para o sistema de gestão de manutenção. Rio de Janeiro, 2012.

CARDOSO, F. S. Estudo da deterioração da pedra na igreja de Paço de Sousa - proposta de tratamento. 2008.117f. Dissertação (Mestrado Integrado em Engenharia Civil) - Departamento de Engenharia Civil, Faculdade de Engenharia da Universidade do Porto, Porto, 2008. Disponível em: https://repositorio-aberto.up.pt/handle/10216/59348. Acesso em: 03 nov. 2019.

GOMIDE, T. L. F.; PUJADAS, F. Z. A.; NETO, J. C. P. F. Técnicas de Inspeção e Manutenção Predial. São Paulo: Editora Pini, 2006.

GROSSI, M. V. F. Direcional Condomínios: Manutenção e reparo de revestimentos de fachada. São Paulo, 2016. Disponível em: https://www.direcionalcondominios.com.br/sindicos/marcus-vinicius-fernandes-grossi/item/2263manutencao-e-reparo-de-revestimentos-de-fachada.html. Acesso em: 05 nov 2019.

IBAPE. Norma de inspeção predial nacional. PUJADAS, F. Z. A. (coord.); SALDANHA, M. S.(coord.). 2012. Disponível em: http://ibape-nacional.com.br/biblioteca/wp-content/uploads/2012/12/Norma-de-Inspe\%C3\%A7\%C 3\%A3o-Predial-IBAPE-Nacional.pdf. Acesso em: 06 nov. 2019.

INSTITUTO DO PATRIMÔNIO HISTÓRICO E ARTÍSTICO NACIONAL. Rotas do Patrimônio: Olinda - Seminário e Igreja de Nossa Senhora da Graça. Brasília, n. 13, 2010.

JC ONLINE. Prédio do seminário de olinda é interditado sob risco de desabamento. Recife, 28 mai. 2015.

Disponível em: https://jconline.ne10.uol.com.br/canal/cidades/geral/noticia/2015/05/28/predio-do-seminario-de-olindae-interditado-sob-risco-de-desabamento-183284.php. Acesso em: 02 ago. 2019.

MENEZES, J. L. Olinda - Igreja de Nossa Senhora da Graça e Seminário de Olinda. O iPatrimônio. 2019. Disponível em: http://www.ipatrimonio.org/wp-content/uploads/2017/05/Olinda-Igreja-de-Nossa-Senhora-da-Gra\%C3\%A7a-eSemin\%C3\%A1rio-de-Olinda-Imagem-Prefeitura-Municipal.jpg. Acesso em: 27 ago. 2019.

NÓBREGA et al. Mapeamento, diagnóstico e soluções de manifestações patológicas em edifício histórico. Estudo de caso: casarão da fazenda maquiné, Araruna - PB. (2017). In: CONGRESSO INTERNACIONAL DA DIVERSIDADE DO SEMIÁRIDO, 1, 2017, Natal. Anais [...]. Disponível em: http://www.editorarealize.com.br/revistas/conidis/ trabalhos/TRABALHO_EV074_MD1_SA11_ID1579_02102017225416.pdf Acesso em: 10 nov. 2019.

ROCHA, E. de A. et al. Adaptation of damages map to historical buildings with pathological problems: Case study of the Carmo's Church in Olinda PE. Revista ALCONPAT, v. 8, n. 1, p. 51-63, 2018.

SALES, A. et al. Corrosão e degradação em estruturas de concreto: Teoria, controle e técnicas de análise e intervenção. Elsevier, Brasil, 2018. 